\title{
Grain Size and Grain Boundary Analysis of Aluminum Compacts with/without 10 wt.\% of Nickel Powder Processed by Equal Channel Angular Pressing
}

\author{
Ü. DEMiR ${ }^{a, *}$, S. AKSÖZ ${ }^{b}$ AND A. GÜRAL ${ }^{c}$ \\ ${ }^{a}$ İncirli Vocational and Technical Anatolian High School, Ankara, Turkey \\ ${ }^{b}$ Pamukkale University, Technology Faculty, Department of Materials Science and Engineering, Denizli, Turkey \\ ${ }^{c}$ Gazi University, Technology Faculty, Department of Metallurgical and Materials Engineering, Ankara, Turkey \\ The aim of this study is to consolidate the Al-Ni powders using the equal channel angular pressing method in \\ order to achieve improved structural and mechanical properties. Thus, both alloying ability at low temperature, \\ as a result of consolidations of ultrafine grained alloy by equal channel angular pressing method, and the average \\ grain size and grain boundary angle have been studied and the effect of Nickel has been investigated. Severe plastic \\ deformation and consolidation process with 15 passes of equal channel angular pressing, having route C, have been \\ carried out at $200^{\circ} \mathrm{C}$ using pure aluminum and aluminum with $10 \mathrm{wt} . \%$ of nickel. Electron backscatter diffraction \\ was used to obtain scanning electron microscopy images and to determine the average grain size and average grain \\ boundary angle. Density measurements of samples have been carried out using the Archimedes principle and the \\ microhardness distributions have been obtained using the HV 0.5 method.
}

DOI: 10.12693/APhysPolA.134.64

PACS/topics: powder, aluminum and nickel, ECAP, consolidation, EBSD

\section{Introduction}

Low cost, lightness, resistance against corrosion, good ductility and aesthetic appearance are the most crucial properties of the Al alloys. Due to these properties, research of these alloys has been undergoing in the academic field and the potential for commercialization of these alloys has increased [1].

A considerable amount of methods and techniques have been developed to improve the properties of $\mathrm{Al}$ and its alloys. In particular the parameters of high purity $\mathrm{Al}$ have been tried to be improved with the help of such mechanisms as synthesis of solid solutions, precipitation hardening/aging, strain hardening and grain refining. Furthermore, numerous researches have been done to produce the extraordinarily fine grains (below $1 \mu \mathrm{m}$ ) with severe plastic deformation (SPD) process [2-4].

A number of studies have been done to produce metallic materials containing ultrafine grain structure using SPD process [5]. A lot of techniques have been discovered to be used in SPD process. The most effective ones, described in scientific studies, are based on equal channel angular pressing (ECAP) [6, 7], equal channel angular extrusion [8], ECAP with back-pressure [9] and ECAP with torsion [10] methods.

The aim of these methods is to obtain ultrafine grain (UFG) structure [11] and due to obtained UFG, according to Hall Petch equation [12, 13], to obtain high mechanical properties caused by the fine grains. When

*corresponding author; e-mail: mitdemir@gmail.com grains reach the fine form, high angle orientation of grains with respect to each other directly helps to prevent shear mechanism and increase dislocation density at the grain boundaries [14].

With the obtained UFG form, in methods similar to ECAP, the addition of the alloying elements to the structure enables one to have a composite structure. This way, grain investigation and composition development can be achieved at the same time and in the same structure [15].

In this study, it is aimed to obtain ultrafine grain structure using ECAP method in pure $\mathrm{Al}$ and $\mathrm{Al}$ with 10 wt.\% of $\mathrm{Ni}$ powders. It is also aimed to obtain $\mathrm{Al}-\mathrm{Ni}$ composite structure in the consolidated form.

\section{Experimental study}

In the study $\mathrm{Al}$ powders (Alfa Aesar) with average grain size of $13.74 \mu \mathrm{m}$ and $99.5 \%$ purity and Ni powders (Alfa Aesar) with average grain size of $11.50 \mu \mathrm{m}$ have been used. The average grain sizes of the powders were determined with Malvern laser particle size analyzer.

In this study the ECAP process was performed by using route $\mathrm{C}$ which has 15 passes (Fig. 1) for pure $\mathrm{Al}$ powder and the mixture of $\mathrm{Al}$ and $\mathrm{Ni}$ powders with 10 wt.\% of $\mathrm{Ni}$ added into pure $\mathrm{Al}$. $\mathrm{Al}$ and 10 wt.\% Ni powders have been mixed for $15 \mathrm{~min}$. in a closed container. Mixed powders have been poured into L shaped channel ECAP form from the open channel space and then packing process with $190 \mathrm{MPa}$ pre-pressing has been performed.

The pressed powders have been heated to $200^{\circ} \mathrm{C}$ together with the form. At this temperature samples have been transferred into the intersection canals, which have been positioned at $90^{\circ}$ angle to the ECAP form, with pressure increasing at a constant rate of $1 \mathrm{~mm} / \mathrm{s}$. By using the ECAP method, the dispersion and consolidation 
of 10 wt.\% of $\mathrm{Ni}$ powders in $\mathrm{Al}$ material and the effects of $\mathrm{Ni}$ powders added to $\mathrm{Al}$ matrix have been analyzed.

The dispersion and effect on grain size of Ni have been examined using scanning electron microscopy (SEM), electron back scatter diffraction (EBSD) analysis and X-Ray diffraction. The JEOL JSM-6060LV model was employed for SEM analysis. EDAX TSL EBSD device was used for EBSD analyses with $60 \mathrm{~nm}$ step interval. For X-ray diffraction analyses APD 2000 PRO XRD has been used.

With the aim of determining the average grain size and the average grain angle in EBSD analyses, the samples have been polished with $6 \mu \mathrm{m}, 3 \mu \mathrm{m}$ and $1 \mu \mathrm{m}$ diamond paste after grinding with sandpaper with 1200 grit size. Later to be able to obtain a better super finishing, surfaces have been polished with colloidal silica suspension with grain size of $0.25 \mu \mathrm{m}$. Finally, the surfaces have been polished by putting them into Struers lectoPol-5 electrolytic polishing device in the solution of $5 \%$ perchloric acid $\left(\mathrm{HClO}_{4}\right), 15 \%$ butoxyethonat $\left(\mathrm{C}_{6} \mathrm{H}_{14} \mathrm{O}_{2}\right)$, $60 \%$ ethanol and $20 \%$ of water and keeping them in it at $22{ }^{\circ} \mathrm{C}$ and $39 \mathrm{~V}$ for ten seconds.

Polished surfaces have been preserved by keeping them in the silica gel in order to prevent oxidation and to keep them clean. Images have been obtained from electrons reflected from the surface and falling on detector as a result of electron bombardment under $70^{\circ}$ angle in EBSD device.

$\mathrm{XRD}$ analyses have been done using $\mathrm{Cu} \mathrm{K}_{\alpha}$ radiation in the range of $5-70^{\circ}$ and using $0.04^{\circ}$ step interval. Archimedes principle has been used in density measurements of produced samples. Microhardness values have been determined in Shimadzu HMV2 microhardness measurement apparatus by applying $50 \mathrm{~g}$ weight with HV 0.5 techniques.

In this study, route $\mathrm{C}$ of the ECAP process has been applied as pressing and operation route (Fig. 1a). Metallographic and micro hardness samples were obtained from material produced by ECAP process (Fig. 1b). Samples for route $\mathrm{C}$ are rotated $180^{\circ}$ after single pass. It is noted that route $\mathrm{C}$ type and channel intersection angle are the most effective methods for the grain refinement [16].

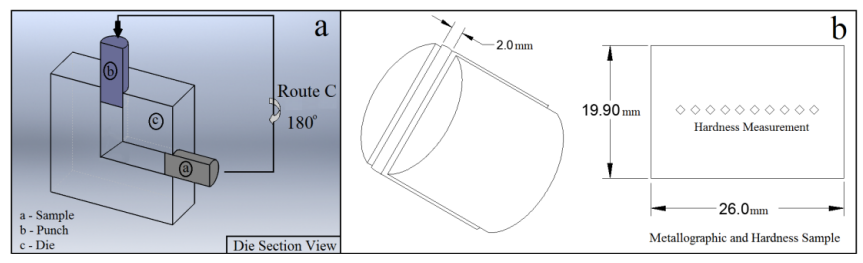

Fig. 1. ECAP process (a), metallographic and micro hardness sample (b).

\section{Results and discussion}

EBSD analyses of pure $\mathrm{Al}$ and $\mathrm{Al}+10$ wt.\% Ni powders after 15 passes in ECAP can be seen in Fig. 2a and b, respectively. As it is seen, with the addition of $10 \mathrm{wt} . \%$ of $\mathrm{Ni}$ an observable refinement has occurred in grains at the same transition rate. Grain refinement and changes in grain angle in the structures have been demonstrated in Fig. 3. When Fig. 3 is examined carefully it can be seen that while the average grain size of pure $\mathrm{Al}$ is $1.73 \mu \mathrm{m}$ (Fig. 3a), the average grain boundary angle is $23.95^{\circ}$ for pure $\mathrm{Al}$ (Fig. 3b). For $\mathrm{Al}+10$ wt.\% Ni alloy (Fig. 3d) the average grain size is $1.56 \mu \mathrm{m}$ (Fig. 3c) and the average grain boundary angle is $27.71^{\circ}$.

It is thus demonstrated that the average grain size for $\mathrm{Al}+10$ wt.\% Ni alloy has been refined considerably and that grain boundary angle was increased significantly. Addition of 10 wt.\% of $\mathrm{Ni}$, as a result of SPD process, has increased dislocation density and has caused formation of thin and high-angle grains by preventing shear mechanism of Al grains [14]. This has been shown based on the fact that the disorientation between the grains has increased with the addition of 10 wt.\% of Ni. Thus, while the amount of high-angle grain boundaries for $\mathrm{Al}$ is $53.18 \%$ after 15 passes, it has been found to be $62.91 \%$ for $\mathrm{Al}+10 \mathrm{wt} . \% \mathrm{Ni}$ alloy after 15 passes.

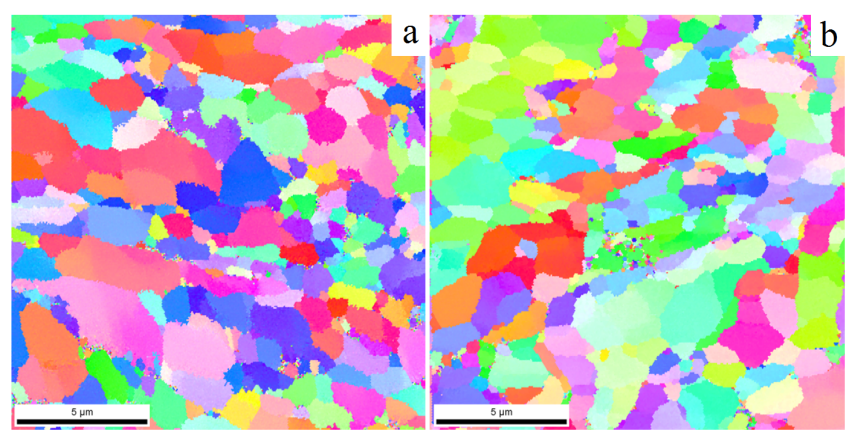

Fig. 2. EBSD images of (a) pure $\mathrm{Al}$, (b) $\mathrm{Al}+10$ wt.\% of Ni.

Optical microscope and SEM images for pure $\mathrm{Al}$ and $\mathrm{Al}+10$ wt.\% Ni samples are presented in Fig. 4. When the images of samples produced of pure $\mathrm{Al}$ powder are examined (Fig. 4a and b), one can clearly see in Fig. 4a the density of deformation lines after the 15 ECAP passes applied.

As it can be seen in Fig. 4c and d, Ni particles have decreased the deformation line sizes to micro size after 15 ECAP passes with $\mathrm{Al}+10$ wt.\% Ni powders. Thus the optical microscope images show that $\mathrm{Ni}$ addition has resulted in a homogenous dispersion in the micro structure (Fig. 4c).

Comparison of relative density-hardness measurements of the samples produced with pure $\mathrm{Al}$ and $\mathrm{Al}+10$ wt.\% $\mathrm{Ni}$ is shown in Fig. 5a. In Fig. 5b the average grain sizes and the average grain boundary angles are compared for samples produced of pure $\mathrm{Al}$ and of $\mathrm{Al}+10 \mathrm{wt} . \%$ $\mathrm{Ni}$. The XRD diagram of Al+10 wt.\% Ni alloy after 15 ECAP passes is shown in Fig. 5c. While $\mathrm{Al}$ and Ni peaks have been obtained in the XRD diagram, no intermetallic phases have been identified in the structure of samples produced under ECAP conditions (at $200^{\circ} \mathrm{C}$ ). 


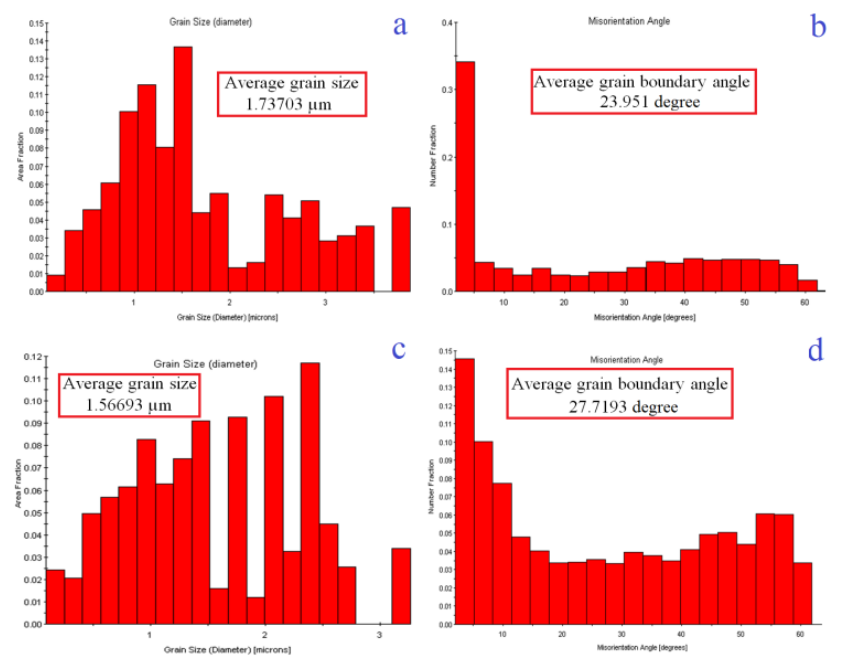

Fig. 3. Average grain sizes of (a) pure Al, (c) $\mathrm{Al}+10 \mathrm{wt} . \% \mathrm{Ni}$, average grain boundary angles of (b) pure $\mathrm{Al}$ and (d) $\mathrm{Al}+10$ wt.\% Ni.

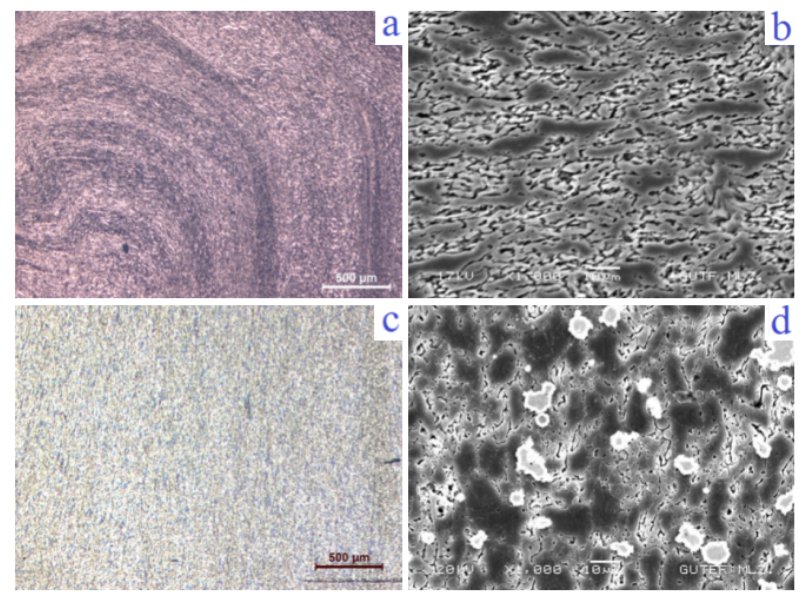

Fig. 4. Optical images of (a) pure $\mathrm{Al}$, (c) $\mathrm{Al}+10$ wt.\% $\mathrm{Ni}$, SEM images of (b) pure Al, (d) Al+10 wt.\% Ni.

The examination of Fig. 5 shows that samples containing $\mathrm{Al}+10$ wt.\% $\mathrm{Ni}$ have a smaller fine grain sizes than those of samples containing $\mathrm{Al}$, increased average grain boundary angle and the increased amount of dislocations. $\mathrm{Al}+10$ wt. $\% \mathrm{Ni}$ alloy containing finer grains has higher hardness values than $\mathrm{Al}[12,13]$. Since there is no complete dissolution between $\mathrm{Al}$ and $\mathrm{Ni}$ in the structure containing $\mathrm{Al}+10$ wt.\% of $\mathrm{Ni}$ after the ECAP process, high dislocation rates in materials as a result of SPD mechanism have a direct effect on the decrease of density.

\section{Conclusions}

In this study, the effects of SPD process on micro structure and mechanical properties for pure $\mathrm{Al}$ and $\mathrm{Al}+10 \%$ $\mathrm{Ni}$ alloys produced using ECAP methods at $200^{\circ} \mathrm{C}$ are studied. The results are summarized below:
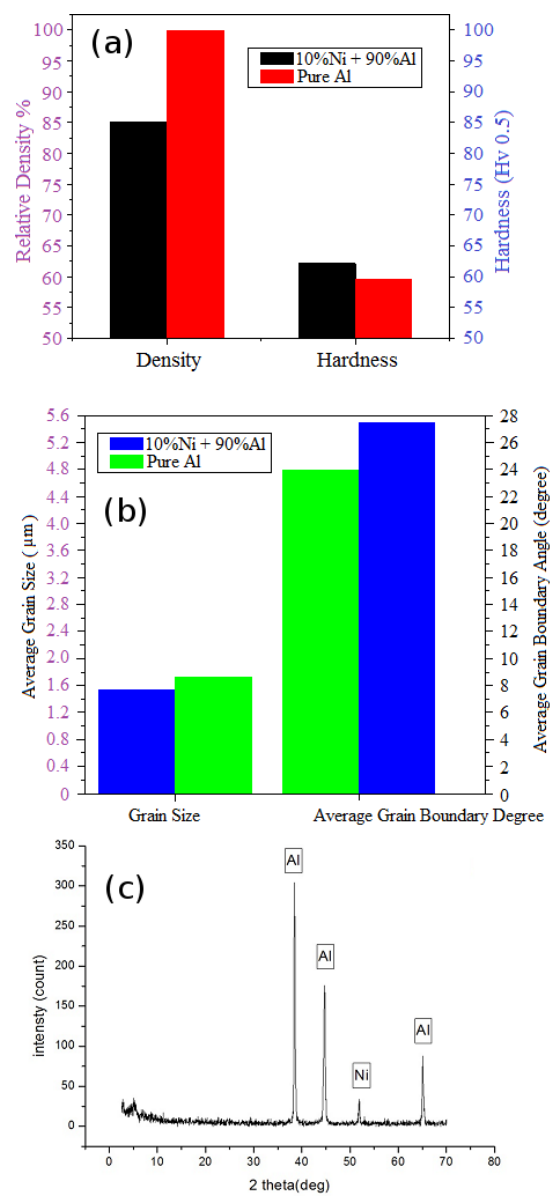

Fig. 5. (a) Relative density-hardness measurement, (b) average grain size and average grain boundary angle of pure $\mathrm{Al}$ and $\mathrm{Al}+10$ wt.\% Ni samples. Figure (c) shows XRD scan of $\mathrm{Al}+10$ wt.\% Ni.

- Finer grain size has been obtained with consolidation in pure $\mathrm{Al}$ and $\mathrm{Al}+10 \mathrm{wt} . \% \mathrm{Ni}$ alloy as a result of SPD process containing 15 passes.

- Finer grain size structure and higher grain boundary angle have been obtained in 10 wt.\% Ni alloy after 15 passes, compared to pure Al. While highangle grain boundary amount has been $53.18 \%$ for pure $\mathrm{Al}$, it has been increased up to $62.91 \%$ with the addition of $10 \mathrm{wt} . \%$ of $\mathrm{Ni}$.

- While $99.9 \%$ density was reached with pure $\mathrm{Al}$ after 15 passes, with the addition of 10 wt.\% of $\mathrm{Ni}$ the density of the alloy has decreased to $84.99 \%$. Hardness values have been found to be $59.62 \mathrm{HV}$ and $62.16 \mathrm{HV}$ for pure $\mathrm{Al}$ and $\mathrm{Al}+10 \mathrm{wt} . \% \mathrm{Ni}$ alloy, respectively.

- While deformation lines have been seen in macro images of pure $\mathrm{Al}$ with a severe deformation process, in Al matrix containing $10 \mathrm{wt} \% \mathrm{Ni}$, deformation line sizes have decreased because particles have decreased their deformation line sizes in macro size. 


\section{References}

[1] A. Taşkesen, S. Aksöz, A.T. Özdemir, Kov. Mater. $\mathbf{5 5}, 57$ (2017).

[2] C.G. de Faria, N.G.S. Almeida, M.T.P. Aguilar, P.R. Cetlin, Mater. Let. 174, 153 (2016).

[3] ASM Handbook, 10th ed. 2, Amer. Soc. Met. - ASM Intern., Ohio 1990.

[4] I. Sabirov, M.Y. Murashkin, R.Z. Valiev, Mater. Sci. Eng. A 560, 1 (2013).

[5] R.Z. Valiev, T.G. Langdon, Prog. Mater. Sci. 51, 881 (2006).

[6] Sh. Valipour, A.R. Eivani, H.R. Jafarian, S.H. Seyedein, M.R. Aboutalebi, Mater. Des. 89, 377 (2016).

[7] Ü. Demir, A. Güral, M.K. Öztürk, J. Fac. Eng. Arch. Gazi Univ. 32(3), 685 (2017).
[8] V.M. Segal, Mater. Sci. Eng. A 271, 322 (1999).

[9] K. Xia, X. Wu, Scri. Mater. 53, 1225 (2005).

[10] M. Khajouei-Nezhad, M.H. Paydar, R. Ebrahimi, P. Jenei, P. Nagy, J. Gubicza, Mater. Sci. Eng. A. 682, 501 (2017).

[11] N. Tsuji, T. Toyoda, Y. Minamino, Y. Koizumi, T. Yamane, M. Komatsu, M. Kiritani, Mater. Sci. Eng. A 350, 108 (2003).

[12] E.O. Hall, Proc. Phys. Soc. B64, 747 (1951).

[13] N.J. Petch, Jour. Iron and Steel Inst. 174, 25 (1953).

[14] B. Tolaminejad, M.M. Hoseini-Athar, Mater. Sci. Eng. A 670, 146 (2016)

[15] S. Mirab, M. Nili-Ahmadabadi, Mater. Sci. Eng. A 583, 43 (2013).

[16] A. Rebhi, T. Makhlouf, N. Njah, Y. Champion, J. Philippe, Mater. Char. 60, 1489 (2009). 